\title{
Presence of hypothyroidism and thyroiditis does not improve the performance of ultrasound screening for thyroid nodules in patients with obesity
}

\author{
Gabriel Gimenez-Perez ${ }^{1}$, Assumpta Recasens ${ }^{1}$, Sandra Chicharro ${ }^{2}$, Olga Simo ${ }^{1}$, Jesus \\ Murillo $^{2}$, and Ignasi Castells ${ }^{1}$ \\ ${ }^{1}$ Hospital General de Granollers \\ ${ }^{2}$ Fundació Privada Hospital de Mollet
}

January 20, 2021

\begin{abstract}
Purpose: It has been suggested, on a theoretical basis, that ultrasound screening of thyroid nodules in obese patients with additional risk factors (family history, thyroiditis or high thyrotropin) might be cost-effective for the early detection and treatment of thyroid cancer. The present study evaluates if this approach can be validated in a real clinical setting. Methods: Patients with obesity attended in hospital-based clinics were evaluated for risk factors of thyroid cancer and ultrasound screened for thyroid nodularity. Detected nodules were evaluated according to current guidelines. Results: A total of 429 patients were evaluated $(70.2 \%$ women, mean age $49.1 \pm 11.0$, mean body mass index $42.6 \pm 5.8 \mathrm{~kg} / \mathrm{m} 2)$. Risk factors were present in 129 (30.1\%) patients. Thyroid nodules with indication for fine needle aspiration biopsy were detected in 69 (16.1\%). We did not find differences in the risk of harbouring thyroid nodules according to the presence of risk factors (no risk factors $16.6 \%$, risk factors $14.1 \%, \mathrm{p}=0.64)$. No single risk factor conferred an increased risk for thyroid nodules During the screening procedure 4 cases of thyroid cancer were detected, none of them with the evaluated risk factors. Conclusion: The present study, has been unable to demonstrate that the use of known risk factors for thyroid cancer is helpful to discriminate obese patients with higher risk of harbouring thyroid nodules.
\end{abstract}

\section{INTRODUCTION}

Obesity is a well-established risk factor for numerous diseases, including different types of cancer [1, 2]. Various studies and meta-analyses have observed an increase in the incidence of differentiated thyroid cancer in overweight and obese individuals [3]. Additionally, it has been suggested that obesity is associated to more aggressive forms of papillary cancer [4], to more advanced stages at diagnosis [5] and to higher rates of disease persistence after treatment [6]. However, these associations have not been replicated in other studies $[7]$.

Ultrasound screening of thyroid cancer is not recommended in asymptomatic individuals with no specific risks for the disease [8], however, some controversy exists about the benefits and risks of the screening in high risk populations such as radiation exposure [9,10] and autoimmune thyroid diseases [11]. Obesity may be also considered a risk factor for thyroid cancer [12], and although the screening of thyroid cancer in obese individuals is not considered justified [13], data about the feasibility of early detection of thyroid cancer by systematic ultrasound assessment and its effects on the prognosis of thyroid cancer in patients with obesity are lacking [13].

In order to justify a specific cancer screening approach, it must be demonstrated that it is beneficial, that it lacks of significant harm and that it is cost-effective [14]. Recently, Cham et al [15], evaluated the cost- 
effectiveness of US screening of thyroid cancer in obese individuals. In their study, using data from published reports and US costs, the authors concluded that US screening of thyroid cancer in selected obese patients with risk factors (family history of thyroid cancer, radiation exposure, Hashimoto's thyroiditis, and/or elevated thyrotropin (TSH)) was cost-effective. However, the study was based on published reports and has not been experimentally validated in actual obese patients.

The objective of the current study is to evaluate if a strategy of US screening of thyroid nodules in obese patients with risk factors, can be validated in a real clinical setting.

\section{MATERIALS AND METHODS}

Patients from the obesity and diabetes clinics of two Endocrinology Units (Hospital General de Granollers and Hospital de Mollet), older than 18 years and with obesity, defined as a body mass index (BMI) [?] 30 $\mathrm{kg} / \mathrm{m}^{2}$, were asked to participate.

After signing the informed consent, patients were examined clinically and a thyroid US and the determination of serum anti-thyroperoxidase antibodies (TPOAb) and TSH levels were planned.

Exclusion criteria were the inability to understand the study, the presence of personality traits in which the practice of thyroid US and the possible detection of nodular pathology could generate an undue anxiety, and the presence of previously other known autoimmune diseases, thyroid nodules or thyroid cancer. Specifically, patients with obesity who consulted for suspected functional or nodular thyroid disease were not included in the present study.

Thyroid US were performed and interpreted by experienced endocrinologists using an Esaote Mylab9 scanner (Hospital de Granollers) or a Siemens Sonoline G40 scanner (Hospital de Mollet) both equipped with a highresolution linear transducer $(7.5-14 \mathrm{MHz})$.

Serum TPOAb were measured in an Immulite 2000 XPi Immunoassay System (Siemens Healthcare GmbH, Erlangen Germany) and expressed as IU/ml. Normal values for TPOAb were $<35 \mathrm{IU} / \mathrm{ml}$. Serum TSH was measured in a Cobas e170 analyser (Roche Diagnostics LTd, Rotkreuz, Switzerland; normal values 0.3-4.2 $\mu \mathrm{IU} / \mathrm{ml})$.

Patients were classified according to neck palpation (i.e. abnormal vs. normal) and the presence of the prespecified risk factors, i.e. family history of thyroid cancer, radiation exposure, Hashimoto's thyroiditis and elevated TSH or treated hypothyroidism. Patients were considered as harbouring Hashimoto's thyroiditis if TPOAb levels were higher than the upper limit of reference. Likewise, TSH levels were considered high if they exceeded the upper normal reference value.

Thyroid nodules detected by thyroid US were classified as specified by the current guidelines of the American Thyroid Association (ATA) [16] and fine needle aspiration biopsy (FNAB) was indicated accordingly, with the exception of subcentimeter nodules with a high suspicion echographic pattern where FNAB was also considered. FNABs were performed and processed using standard protocols [17] and were evaluated by the Department of Pathology of Hospital de Granollers using the Bethesda reporting system [18]. Surgical treatment was planned according to current guidelines [16]. In a post-hoc analysis nodules were classified following the TI-RADS classification of the American College of Radiology (ACR) [19].

Follow-up of nodules not subjected to surgery and of those without indication of FNAB was performed at discretion of the attending physician.

Data are presented as number (n) and standard deviation (SD) or percentages with $95 \%$ confidence intervals (CI) when appropriate. The differences in the frequency of thyroid nodules between groups were analysed with Pearson's Chi-squared test at a significance level of $\mathrm{p}<0.05$. To test for differences between the present results and those previously hypothesized we used inference statistics for one sample using as reference the proportions stated by Cham et al [15]. Analyses were performed using free online statistical packages (https://www.socscistatistics.com and https://www.medcalc.org/calc/test_one_proportion.php). 
The study was approved by the research committees of the participating centres. No specific funding was received for the development of the study.

\section{RESULTS}

During the study period, participation was offered to a total of 506 patients, of whom 429 were valid for evaluation. Figure 1 depicts the flow diagram of the study and the classification of the evaluated patients according to their risk factors. The final population consisted of $301(70.2 \%)$ women and $128(29.8 \%)$ men with a mean age of $49.1 \pm 11.0$ years and a BMI of $42.6 \pm 5.8 \mathrm{~kg} / \mathrm{m}^{2}$. Morbid obesity (BMI[?] $40 \mathrm{~kg} / \mathrm{m}^{2}$ ) was present in 283 (66.2\%) patients. As shown, 129 (30.1\%; CI 25.9-34.6) patients were classified as having one or more risk factors for thyroid cancer. Abnormal palpation was present in 38 (8.9\%; CI 6.5-11.9) individuals. Elevated TSH/hypothyroidism was the most prevalent risk factor (19.6\%; CI 16.1-23.6). Prevalence of risk factors was significantly higher among women $(34.4 \%$ vs $17.4 \%$; $<0.001)$. Radiation exposure was not present in any patient.

Sixty-nine (16.1\%; CI 12.8-19.9) patients harboured thyroid nodules with indication for FNAB according to the ATA guideline [16]. This value was significantly higher than expected $(10 \% ; \mathrm{P}<0.0001)$ [15]. Prevalence of thyroid nodules was significantly higher in women $(18.9 \%$ vs $9.4 \% ; \mathrm{P}=0.014)$. Patients with thyroid nodules were significantly older $(54.2 ? 10.0$ vs. $48.2 ? 12.1 ; \mathrm{P}<0.005)$. Body mass index was not different between patients with or without thyroid nodules $(\mathrm{P}=0.49)$.

Sixty-three patients underwent FNAB. Table 1 shows the FNAB results, the corresponding US risk categories and the final surgical diagnosis when available. Initially, six nodules received a Bethesda 3 diagnosis, which was confirmed in a second FNAB in 2 cases; the second FNAB of the four remaining nodules rendered a Bethesda 2 diagnosis.

Six patients were lost for follow-up before performing the FNAB; two of these nodules were classified as high suspicion pattern according to the ATA guideline (moderately suspicious according to ACR) with a maximum diameter of $12 \mathrm{~mm}$.

Four patients were operated on the basis of cytological results with 3 final cases of papillary thyroid cancer and one case of nodular hyperplasia (cytological diagnosis: Bethesda 4). The clinical and pathological characteristics of papillary thyroid cases are shown in Table 2. An additional case was operated despite a benign FNAB result on the basis of mild local symptoms with a final result of nodular hyperplasia.

In $111(25.9 \%)$ patients, thyroid nodules with no indication of FNAB were found. In $48(43.2 \%)$ patients follow-up sonographies were performed after a median time of 14 months. During follow-up, 26 months after the initial screening, we detected enlarged suspicious lymphadenopathies in a 47yr old male patient with a hypoechoic isthmic nodule of $8 \mathrm{~mm}$. The final diagnosis was papillary thyroid carcinoma (multicentric, infiltrative follicular variant) pT1bN1bM0 with a largest nodule of $11 \mathrm{~mm}$. At first evaluation, TSH was normal and TPOAbs were undetectable. Therefore, risks of malignancy were $0.93 \%$ (CI $0.02-1.84$ ) for the entire screened cohort; $2.2 \%$ (CI 0.9-5.5) for patients with thyroid nodules and 5.8\% (CI 2.3-14.0) for those nodules with indication of FNAB.

Table 3 depicts the percentage of thyroid nodules according to thyroid palpation and risk factors. As shown, the presence of an abnormal palpation was associated with a significantly higher prevalence of thyroid nodules, whereas the prevalence of thyroid nodules was not dependent on the presence of risk factors. Additional comparisons considering as risk factor a TPOAb level above $100 \mathrm{IU} / \mathrm{ml}$ and excluding patients with treated hypothyroidism did not find significant differences between groups in the prevalence of thyroid nodules.

Table 4 shows the prevalence of thyroid nodules according to the individual risk factors. The presence of thyroid nodules was, again, not dependent on the presence of any of the assessed risk factors.

\section{DISCUSSION}


In the present study, we have not been able to demonstrate that the use of established risk factors for thyroid cancer is useful to discriminate obese patients with a higher risk of harbouring thyroid nodules and, therefore candidates to rule out thyroid cancer.

No professional medical society recommends population-based screening for thyroid cancer [20], and in the cases where this strategy has been implemented it has rendered no benefit in clinical terms [21]. However, there is a continued increase in thyroid cancer prevalence in most countries that is generally considered as overdiagnosis and overtreatment [22] and probably indicates, among other reasons, a continued nonjudicious use of thyroid ultrasound in some clinical settings $[23,24]$. Our aim in this study was to analyse the effectiveness of a screening strategy advocated as cost-effective and therefore recommendable from a theoretical framework [15], adding knowledge to the sensible use of thyroid ultrasound. Our data do not support the advocated strategy and therefore supports the current recommendations in asymptomatic obese adults [13].

A significant difference between the theoretical framework used in the seminal study [15] and our actual results is the prevalence of risk factors. The main discrepancy lies in our higher prevalence of hypothyroidism. Although the prevalence of high TSH may be different in different populations [25, 26], the reported prevalences, also for treated hypothyroidism [27], are generally lower than in our study. A possible explanation for our higher prevalence could be the presence of obesity itself, since it has been reported that high TSH levels are more prevalent in obese patients, at least in children and adolescents [28] and morbid obese patients [29]. The prevalence of TPOAb was similar to some other studies [26] but again higher than usually expected.

Different studies have shown an association between thyroid cancer and the presence of autoimmune thyroiditis [30, 31] or higher TSH levels [32]. Although these associations are not a constant finding [33, 34], some authors have suggested a role for periodic US to detect thyroid malignancy in these situations [30]. In our population the presence of these potential risk factors was not associated to an increased risk of thyroid nodularity or cancer. We can hypothesize that this finding may be due to a different relevance of these factors in the obese population, specially the higher incidence of high TSH. In this sense it has been argued that higher TSH levels in obese patients are not an evidence of thyroid dysfunction but, rather, an adaptation process [35]. Interestingly, in a recent report, thyroid nodules were less common in children and adolescents with autoimmune thyroiditis or high TSH than in their counterparts [36].

The percentage of thyroid nodules with indication for FNAB was higher than expected [15]. This result is in line with other authors' results [37] and suggests that the prevalence of thyroid nodularity in the obese population is probably higher than in the non-obese population.

Several meta-analyses have found an association of obesity with an increased thyroid cancer risk [3]. Although the present study was not designed nor powered to evaluate the incidence of thyroid cancer or the utility of generalized US screening for its detection in obese patients, we found an incidence above the reported incidence rates for the general population [8] although in line with other populations where a systematic screening has been performed [21]. Most detected thyroid cancers in our study were of low risk and good prognosis and since any screening strategy should counterbalance potential health benefits with the risk of generating an excess in diagnosis, treatment and costs $[8,21]$, it does not seem that any screening strategy of thyroid cancer in obese individuals will be cost-effective and, in any case, the use of the assessed risk factors is not useful.

Furthermore, this screening strategy results in the detection of a considerable number of nodules without indication for FNAB that could be subjected to follow-up increasing resource use and costs and generating anxiety for patients without any noticeable benefit.

Our study has some limitations. We designed the study to detect differences in the incidence of thyroid nodules and not thyroid cancer, which is the final purpose of the screening strategy. However, detection of thyroid nodules is the first step in the diagnosis of most thyroid cancers [16] and therefore the absence of an increased incidence of thyroid nodules in the obese population with additional risk factors makes the screening strategy ineffective. 
Some variability may rise from the fact that ultrasound was not performed centrally. However, the use of a specific classification system might have reduced the effects of this limitation [38].

Additionally, we used as a surrogate for the presence of thyroiditis the positivity of TPOAb. Although other serological markers can be used, TPOAbs are considered the best serological marker to establish a diagnosis of Hashimoto's thyroiditis [39]. However, an association between thyroid cancer and anti-thyroglobulin antibodies $(\mathrm{TgAb})$ has been reported [31], and therefore we cannot rule out that the use of TgAbs would have changed the results.

Also, the population studied is predominantly morbid obese patients, which may not be representative of other obese populations. It seems reasonable, however, to consider that our study focuses on the obese population at highest risk of cancer and in which the effect of additional risk factors should be more evident. Moreover, BMI was not different between patients without or with thyroid nodules.

Furthermore, there is some risk of selection bias. For unknown reasons, not all obese patients attended were offered participation and, this fact may have selected the population finally evaluated. Additionally, we decided to exclude patients with other autoimmune diseases. The reason for doing so, was to not overestimate de prevalence of high TPOAbs as it is known that the prevalence of thyroid autoimmunity is increased in the presence of other autoimmune disorders [40].

Despite these limitations, the number of patients evaluated give us confidence that the results are reliable and therefore we can conclude that the use of the studied risk factors (specifically TSH and TPO) is not useful to discriminate obese patients with a higher risk of harbouring thyroid nodules.

\section{DECLARATIONS}

\section{Funding}

No funding was received for conducting this study

\section{Conflicts of interest}

The authors have no relevant financial or non-financial interests to disclose

\section{Ethics approval}

Approval was obtained from the research committees of the participating centres. The procedures used in this study adhere to the tenets of the Declaration of Helsinki.

Informed consent was obtained from all individual participants included in the study

\section{Authors' contributions}

GGP designed the study protocol and drafted the manuscript. AR, SC, OS, JM and IC reviewed and amended the study protocol. All authors were involved in the acquisition and treatment of data and read and approved the final manuscript.

\section{Data availability}

The data that support the findings of this study are available from the corresponding author upon reasonable request.

\section{REFERENCES}


1- Renehan AG, Tyson M, Egger M, Heller R, Zwahlen M: Body-mass index and incidence of cancer: a systematic review and meta-analysis of prospective observational studies. Lancet 2008;371:569-578.

2- Hidayat K, Du X, Shi: BM Body fatness at a young age and risks of eight types of cancer: systematic review and meta-analysis of observational studies. Obes Rev . 2018;19:1385-1394.

3- Ma J, Huang M, Wang L, Ye W, Tong Y, Wang H: Obesity and risk of thyroid cancer: evidence from a meta-analysis of 21 observational studies. Med Sci Monit. 2015;21:283-91.

4- Wu C, Wang L, Chen W, Zou S, Yang A. Associations between body mass index and lymph node metastases of patients with papillary thyroid cancer: A retrospective study. Medicine (Baltimore) . 2017;Mar;96(9):e6202.

5- Dieringer P, Klass EM, Caine B, Smith-Gagen J: Associations between body mass and papillary thyroid cancer stage and tumor size: a population-based study. J Cancer Res Clin Oncol . 2015;141:93-8.

6- Tresallet C, Seman M, Tissier F, Buffet C, Lupinacci RM, Vuarnesson H, Leenhardt L, Menegaux F: The incidence of papillary thyroid carcinoma and outcomes in operative patients according to their body mass indices.Surgery. 2014;156:1145-52.

7- Grani G, Lamartina L, Montesano T, Ronga G, Maggisano V, Falcone R, Ramundo V, Giacomelli L, Durante C, Russo D, Maranghi M: Lack of association between obesity and aggressiveness of differentiated thyroid cancer. J Endocrinol Invest. 2019;42:85-90.

8- US Preventive Services Task Force, Bibbins-Domingo K, Grossman DC, Curry SJ, Barry MJ, Davidson KW, et al: Screening for Thyroid Cancer: US Preventive Services Task Force Recommendation Statement JAMA . 2017;317:1882-1887.

9- Clement SC, Kremer LCM, Verburg FA, Simmons JH, Goldfarb M, Peeters RP, et al: Balancing the benefits and harms of thyroid cancer surveillance in survivors of childhood, adolescent and young adult cancer: Recommendations from the International Late Effects of Childhood Cancer Guideline Harmonization Group in collaboration with the PanCareSurFup Consortium. Cancer Treat Rev . 2018;63:28-39.

10- Yamashita S, Suzuki S, Suzuki S, Shimura H, Saenko V. Lessons from Fukushima latest findings of thyroid cancer after the Fukushima nuclear power plant accident. Thyroid . 2018;28:11-22.

11- Mukasa K, Noh JY, Kunii Y, Matsumoto M, Sato S, Yasuda S, Suzuki M, Ito K, Ito K: Prevalence of malignant tumors and adenomatous lesions detected by ultrasonographic screening in patients with autoimmune thyroid diseases. Thyroid. 2011;21:37-41.

12- Han JM, Kim TY, Jeon MJ, Yim JH, Kim WG, Song DE, Hong SJ, Bae SJ, Kim HK, Shin MH, Shong YK, Kim WB: Obesity is a risk factor for thyroid cancer in a large, ultrasonographically screened population. Eur J Endocrinol. 2013;168:879-86.

13- Pasquali R, Casanueva F, Haluzik M, van Hulsteijn L, Ledoux S, Monteiro MP, Salvador J, Santini F, Toplak H, Dekkers OM: European Society of Endocrinology Clinical Practice Guideline: Endocrine work-up in obesity. Eur J Endocrinol. 2020;182:G1-G32.

14- Pinsky PF: Principles of cancer screening. Surg Clin North Am . 2015;95:953-66.

15- Cham S, Zanocco K, Sturgeon C, Yeh MW, Harari A: Risk-based ultrasound screening for thyroid cancer in obese patients is cost-effective. Thyroid . 2014;24:975-86.

16- Haugen BR, Alexander EK, Bible KC, Doherty GM, Mandel SJ, Nikiforov YE, et al: 2015 American Thyroid Association management guidelines for adult patients with thyroid nodules and differentiated thyroid cancer: The American Thyroid Association Guidelines Task Force on thyroid nodules and differentiated thyroid cancer. Thyroid.2016;26:1-133. 
17- Castells I, Pardo N, Videla S, Gimenez G, Llargues E, Simo O, Recasens MA, Guirao X, Mira X, Serrano A, Sanmarti A: Healthcare impact of introduction of thyroid ultrasound in a thyroid nodule pathology unit. Endocrinol Nutr . 2013;60:53-9.

18- Cibas ES, Ali SZ: NCI Thyroid FNA State of the science conference. The Bethesda system for reporting thyroid cytopathology. Am J Clin Pathol . 2009;132:658-65.

19- Tessler FN, Middleton WD, Grant EG, Hoang JK, Berland LL, Teefey SA, et al: ACR Thyroid imaging, reporting and data system (TI-RADS): White paper of the ACR TI-RADS Committee. Am Coll Radiol . 2017;14:587-595.

20- Lin JS, Bowles EJA, Williams SB, Morrison CC: Screening for Thyroid Cancer: Updated Evidence Report and Systematic Review for the US Preventive Services Task Force. JAMA . 2017;317:1888-1903.

21- Ahn HS, Kim HJ, Kim KH, Lee YS, Han SJ, Kim Y, Ko MJ, Brito JP: Thyroid cancer screening in South Korea increases detection of papillary cancers with no impact on other subtypes or thyroid cancer mortality. Thyroid . 2016;26:1535-1540.

22- O'Grady TJ, Gates MA, Boscoe FP: Thyroid cancer incidence attributable to overdiagnosis in the United States 1981-2011. Int J Cancer . 2015;137:2664-73.

23- Cronan JJ: Thyroid nodules: is it time to turn off the US machines? Radiology . 2008;247:602-4.

24- Morgan DJ, Dhruva SS, Wright SM, Korenstein D: Update on Medical Practices That Should Be Questioned in 2015. JAMA Intern Med . 2015;175:960-4.

25- Canaris GJ, Manowitz NR, Mayor G, Ridgway EC: The Colorado thyroid disease prevalence study. Arch Intern Med . 2000;160:526-34.

26- Hollowell JG, Staehling NW, Flanders WD, Hannon WH, Gunter EW, Spencer CA, Braverman LE: Serum TSH, T(4), and thyroid antibodies in the United States population (1988 to 1994): National Health and Nutrition Examination Survey (NHANES III). J Clin Endocrinol Metab2002;87:489-99.

27- Giorda CB, Carna P, Romeo F, Costa G, Tartaglino B, Gnavi R: Prevalence, incidence and associated comorbidities of treated hypothyroidism: an update from a European population. Eur $J$ Endocrinol . 2017;176:533-542.

28- Dekelbab BH, Abou Ouf HA, Jain I: Prevalence of elevated thyroid-stimulating hormone levels in obese children and adolescents.Endocr Pract . 2010;16:187-90.

29- Valdes S, Maldonado-Araque C, Lago-Sampedro A, Lillo-Munoz JA, Garcia-Fuentes E, Perez-Valero V, et al: Reference values for TSH may be inadequate to define hypothyroidism in persons with morbid obesity: Di@bet.es study. Obesity (Silver Spring). 2017;25:788-793.

30- Mukasa K, Noh JY, Kunii Y, Matsumoto M, Sato S, Yasuda S, Suzuki M, Ito K, Ito K: Prevalence of malignant tumors and adenomatous lesions detected by ultrasonographic screening in patients with autoimmune thyroid diseases Thyroid. 2011;21:37-41.

31- Azizi G, Keller JM, Lewis M, Piper K, Puett D, Rivenbark KM, Malchoff CD: Association of Hashimoto's thyroiditis with thyroid cancer.Endocr Relat Cancer . 2014;21:845-52.

32- Haymart MR, Repplinger DJ, Leverson GE, Elson DF, Sippel RS, Jaume JC, Chen H: Higher serum thyroid stimulating hormone level in thyroid nodule patients is associated with greater risks of differentiated thyroid cancer and advanced tumor stage. J Clin Endocrinol Metab . 2008;93:809-14.

33- Del Rio P, Montana Montana C, Cozzani F, Rossini M, Loderer T, Dall'Aglio E, Cataldo S, Marina M, Graziano C: Is there a correlation between thyroiditis and thyroid cancer? Endocrine . 2019;66:538-541. 
34- Shi L, Li Y, Guan H, Li C, Shi L, Shan Z, Teng W: Usefulness of serum thyrotropin for risk prediction of differentiated thyroid cancers does not apply to microcarcinomas: results of 1,870 Chinese patients with thyroid nodules. Endocr J. 2012;59:973-80.

35- Reinehr T: Obesity and thyroid function. Mol Cell Endocrinol . 2010;316:165-71.

36- Allen N, Desai N, Song C, Yu J, Prasad U, Francis G: Clinical features may help to identify children and adolescents with greatest risk for thyroid nodules. J Endocrinol Invest . 2020;43:925-934.

37- Buscemi S, Massenti FM, Vasto S, Galvano F, Buscemi C, Corleo D, Barile AM, Rosafio G, Rini N, Giordano C: Association of obesity and diabetes with thyroid nodules. Endocrine . 2018;60:339-347.

38- Grani G, Lamartina L, Cantisani V, Maranghi M, Lucia P, Durante C: Interobserver agreement of various thyroid imaging reporting and data systems. Endocr Connect . 2018;7:1-7.

39- Caturegli P, De Remigis A, Rose NR: Hashimoto thyroiditis: clinical and diagnostic criteria. Autoimmun Rev . 2014;13:391-7.

40- Nakamura H, Usa T, Motomura M, Ichikawa T, Nakao K, Kawasaki E, Tanaka M, Ishikawa K, Eguchi K: Prevalence of interrelated autoantibodies in thyroid diseases and autoimmune disorders. $J$ Endocrinol Invest. 2008;31:861-5.

Table 1. FNAB results, US risk categories (ATA and ACR classification) and final diagnosis

\begin{tabular}{|c|c|c|c|c|}
\hline FNAB result & $\mathrm{n}(\%)$ & $\begin{array}{l}\text { ATA classification } \\
\text { suspicion level (n) }\end{array}$ & $\begin{array}{l}\text { ACR classification } \\
\text { suspicion level (n) }\end{array}$ & Final diagnosis $(\mathrm{n})$ \\
\hline Bethesda 6 & $3(4.3)$ & $\begin{array}{l}\text { High }=2 \\
\text { Intermediate }=1\end{array}$ & $\begin{array}{l}\text { High }=2 \text { Moderate } \\
=1\end{array}$ & $\begin{array}{l}\text { Papillary carcinoma } \\
=3\end{array}$ \\
\hline Bethesda 4 & $1(1.4)$ & Intermediate $=1$ & Moderate $=1$ & $\begin{array}{l}\text { Thyroid } \\
\text { hyperplasia = } 1\end{array}$ \\
\hline Bethesda 3 & $2(2.9)$ & Intermediate $=2$ & Moderate $=2$ & \\
\hline Bethesda 2 & $55(79.7)$ & $\begin{array}{l}\text { High }=10 \\
\text { Intermediate }=18 \\
\text { Low }=24 \text { Very low } \\
=3\end{array}$ & $\begin{array}{l}\text { High }=6 \text { Moderate } \\
=22 \text { Mild }=18 \text { Not } \\
\text { suspicious/benign }= \\
9\end{array}$ & $\begin{array}{l}\text { Thyroid hyperplasia } \\
=1\end{array}$ \\
\hline Bethesda 1 & $2(2.9)$ & $\begin{array}{l}\text { Intermediate }=1 \\
\text { Very low }=1\end{array}$ & $\begin{array}{l}\text { Moderate }=1 \text { Not } \\
\text { suspicious } / \text { benign }= \\
1\end{array}$ & \\
\hline Not performed & $6(8.7)$ & $\begin{array}{l}\text { High }=2 \\
\text { Intermediate }=2 \\
\text { Low }=2\end{array}$ & $\begin{array}{l}\text { Moderate }=4 \text { Mild } \\
=2\end{array}$ & \\
\hline
\end{tabular}

FNAB: Fine needle aspiration biopsy. ATA: American Thyroid Association. ACR: American College of Radiology.

Table 2. Clinical and pathological characteristics of screen detected papillary cancers

\begin{tabular}{llllll}
\hline & Age & Sex & BMI & $\begin{array}{l}\text { TNM (AJCC } \\
\text { 8th ed) }\end{array}$ & $\begin{array}{l}\text { Other } \\
\text { characteristics }\end{array}$ \\
\hline Case 1 & 56 & Male & 38.3 & $\begin{array}{l}\text { pT1bN0 } \\
(16 \mathrm{~mm})\end{array}$ & Classical \\
Case 2 & 53 & Female & 43.2 & pT1bN0 (13mm) & $\begin{array}{l}\text { Classical } \\
\text { Multicentric }\end{array}$
\end{tabular}




\begin{tabular}{|c|c|c|c|c|c|}
\hline & Age & Sex & BMI & $\begin{array}{l}\text { TNM (AJCC } \\
\text { 8th ed) }\end{array}$ & $\begin{array}{l}\text { Other } \\
\text { characteristics }\end{array}$ \\
\hline Case 3 & 36 & Male & 37.9 & pT1bN0 $(13 \mathrm{~mm})$ & $\begin{array}{l}\text { Classical } \\
\text { Multicentric } \\
\text { Focal infiltration } \\
\text { of perithyroidal } \\
\text { soft tissue }\end{array}$ \\
\hline Case $4^{+}$ & 47 & Male & 48.9 & $\begin{array}{l}\text { pT1bN1bM0 (11 } \\
\text { mm) }\end{array}$ & $\begin{array}{l}\text { Infiltrative } \\
\text { follicular } \\
\text { Multicentric } \\
\text { Infiltration of fat } \\
\text { perithyroidal } \\
\text { tissue Lymph } \\
\text { node metastasis } \\
\text { in } 12 \text { out of } 18 \\
\text { lymph nodes }\end{array}$ \\
\hline
\end{tabular}

+ detected during follow-up

BMI: body mass index

Table 3. Prevalence of thyroid nodules according to risk categories

THYROID NODULES WITH INDICATION FOR FNAB n (\%; CI

Abnormal palpation $(\mathrm{n}=38)$

$18(47.4 ; 32.5-62.7)^{*}$

With risk factors (independent of palpation) $(\mathrm{n}=129) \quad 19(14.7 ; 9.6-21.9)^{* *}$

No risks factors (independent of palpation) $(\mathrm{n}=300) \quad 50(16.7 ; 12.9-21.3)$

FNAB: fine needle aspiration biopsy. CI: $95 \%$ confidence intervals. ${ }^{*} \mathrm{p}<0.0001$ vs. normal palpation; ${ }^{* *} \mathrm{p}=0.62$ vs. no risks factors (independent of palpation)

Table 4. Prevalence of thyroid nodules according to individual risk factors

\begin{tabular}{lll}
\hline & Family history of thyroid cancer & Family history of thyroid cancer \\
\hline & YES n $=4$ & NO $\mathrm{n}=425$ \\
Thyroid nodules with indication for FNAB (n (\%)) & $1(25.0 \%)$ & $68(16.0 \%)$ \\
Papillary thyroid cancer (n) & 0 & 3 \\
\hline
\end{tabular}

TSH: thyrotropin; TPOAb: serum anti-thyroperoxidase antibodies; ${ }^{*} \mathrm{P}=0.034$

\section{FIGURE LEGENDS}

Figure 1. Flow diagram of the study

\section{Hosted file}

gimenez_perez_table1IJCP.pdf available at https://authorea.com/users/390699/articles/504937presence-of-hypothyroidism-and-thyroiditis-does-not-improve-the-performance-ofultrasound-screening-for-thyroid-nodules-in-patients-with-obesity

\section{Hosted file}


gimenez_perez_table2IJCP.pdf available at https://authorea.com/users/390699/articles/504937presence-of-hypothyroidism-and-thyroiditis-does-not-improve-the-performance-ofultrasound-screening-for-thyroid-nodules-in-patients-with-obesity

\section{Hosted file}

gimenez_perez_table3IJCP.pdf available at https://authorea.com/users/390699/articles/504937presence-of-hypothyroidism-and-thyroiditis-does-not-improve-the-performance-ofultrasound-screening-for-thyroid-nodules-in-patients-with-obesity

\section{Hosted file}

gimenez_perez_table4IJCP.pdf available at https://authorea.com/users/390699/articles/504937presence-of-hypothyroidism-and-thyroiditis-does-not-improve-the-performance-ofultrasound-screening-for-thyroid-nodules-in-patients-with-obesity

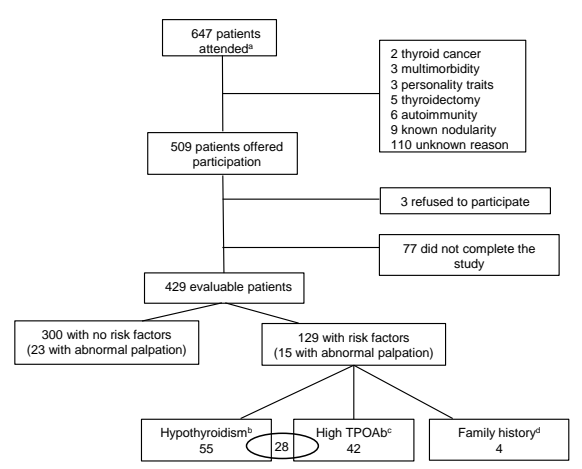

aObese patients attended at the obesity or diabetes clinics

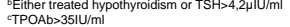
$d_{2}$ patients with high TPOAb (one of them with treated
hypothyoridism) 